\title{
Los "obreros blancos" en Chile. El mutualismo y el cooperativismo entre las décadas de 1940 y 1960
}

\author{
The 'white workers' in Chile. Mutualism and cooperativism \\ between the 1940 s and 1960 s
}

Sebastian Leiva Flores

Universidad de Santiago de Chile

Enviado: 28/04/2019

Aceptado: 25/06/2019

Resumen: Desde mediados del siglo XX se comenzó a estudiar sistemáticamente a los trabajadores chilenos, priorizándose, por los compromisos políticos e influencias del marxismo de esos primeros investigadores, en los "obreros rojos", aquellos que habían formado y nutrido a las centrales sindicales, huelgas y partidos populares. Esa opción, sin embargo, llevó a la invisibilización de esa amplia y diversa masa de trabajadores que no se sindicalizaron o no acotaron su actividad sólo al sindicato y a las organizaciones donde se ha concentrado la historiografía: los "obreros blancos". En esa dirección, este artículo pretende explorar en aquellas agrupaciones, como las mutuales y cooperativas, donde esos trabajadores convergieron, espacios significativos que entre las décadas de 1940 y 1960 nuclearon a varios miles de socios, ensayando hábitos e intereses distintos a los que había promovido el sindicalismo de línea más clasista.

Palabras claves: Trabajadores, “obreros blancos”, mutualismo, cooperativismo

Summary: From the mid-twentieth century, it began to study about Chilean workers systematically, prioritizing, by the political commitments and influences of Marxism of those early researchers, the "red workers", those who had formed and nurtured the trade union centers, strikes and popular parties. However, that option led to the invisibilization of that wide and diverse mass of workers who did not 
unionize or did not limit their activity only to the union and the organizations where the historiography has been concentrated: the "white workers". In that direction, this article aims to explore in those groups, such as mutuals and cooperatives, where those workers converged, between the 1940s and 1960s significant spaces numbered several thousand of members, rehearsing habits and different interests that the most classist unionism had promoted.

Keywords: Workers, "white workers", mutualism, cooperativism

\section{Introducción:}

La clase obrera chilena comenzó a ser estudiada sistemáticamente por los historiadores nacionales desde la década del 50 del siglo $\mathrm{XX}^{1}$, concentrándose en los trabajadores que se incorporaron a los procesos de organización, movilización y politización que fueron impulsando los partidos y líderes de izquierda, los "obreros rojos", proyectados, en esos escritos, como motor, dirección y representación de los sectores más importantes de la fuerza laboral.

Quienes realizaron esos estudios - Julio César Jobet, Hernán Ramírez Necochea, Jorge Barría y Luis Vitale ${ }^{2}$, entre otros-, lo hicieron en los años en que confluyeron dos importantes procesos: la maduración de una estrategia, en el campo de la izquierda, que se expresó en la formación de referentes políticos y sociales como el FRAP y la CUT3 3 y, segundo, en la posición que fue alcanzando el marxismo como matriz de análisis de la realidad, permeando no sólo al campo de la política, sino también al ámbito de las ciencias sociales. En ese contexto y bajo esas influencias, sus investigaciones se concentraron en el proletariado industrial y minero, los cuales

\footnotetext{
${ }^{1}$ Sobre el particular, ver el artículo de Jorge Rojas, Los trabajadores en la historiografía chilena: balances y proyecciones (2000). Revista de Economía y Trabajo, No 10, 2000, pp. 47 - 117.

2 JOBET, Julio Cesar, Recabarren y los orígenes del movimiento obrero y el socialismo chilenos (1955); RAMIREZ, Hernán, Historia del movimiento obrero en Chile: antecedentes siglo XIX (1956) y Origen y formación del Partido Comunista de Chile: ensayo de historia del Partido (1965); BARRIA, Jorge, Los movimientos sociales de Chile desde 1910 hasta 1926 (aspecto político y social) (1960) y El movimiento obrero en Chile (1971); y, VITALE, Luis, Interpretación marxista de la historia de Chile (1967).

${ }^{3}$ El Frente de Acción Popular se creó en 1956, convergiendo en él, el Partido Comunista, Socialista Popular y Socialista de Chile, Radical Doctrinario, Democrático del Pueblo y Democrático, además de otras organizaciones más pequeñas. La Central Única de Trabajadores, por su parte, se creó en 1953, participando en ella, comunistas, socialistas, radicales, socialcristianos, independientes y anarcosindicalistas.
} 
pasaron a constituirse "en los grandes protagonistas de la historia de la salvación y redención de la humanidad", como señala Jorge Rojas4, quedando al margen de su mirada aquellos trabajadores que se incorporaron tarde al proceso de modernización capitalista, como los campesinos.

Influidos por sus orientaciones políticas y matrices de análisis, junto a los campesinos quedaron también fuera de su mirada aquellos trabajadores que no se incorporaron a los espacios y dinámicas impulsados por los partidos y líderes de izquierda, los "obreros blancos", quienes adscribieron al mutualismo, el sindicalismo católico, las federaciones independientes y el sindicalismo "puro", y se manifestaron poco partidarios del expediente de la huelga. Una cantidad de trabajadores que, desde la óptica que se mire, era importante, y que pasó eventualmente a nutrir los apoyos de las corrientes reformistas, nacionalistas y estatistas que asomaron en la primera mitad del siglo XX. En relación a ello, numerosas investigaciones, diversas en sus temas y años de publicación, han dado cuenta que muchos trabajadores se identificaron con corrientes escasamente rupturistas y líderes no "populares", como el liberal balmacedismo de comienzos del siglo en la politización "desde arriba" a la cual refiere Julio Pinto, o el reformismo de Arturo Alessandri que se observa en sus estudios con Verónica Valdivia, inaugurando el líder liberal las políticas sociales del Estado. Jorge Rojas, a su vez, dio cuenta de las simpatías que significativos gremios y organizaciones obreras de los años veinte y treinta del siglo pasado, manifestaron por el general, presidente y dictador Carlos Ibáñez del Campo, quien profundizó las funciones sociales que se le estaban asignando al Estado. Por su parte, en estudios de Rafael Sagredo y Maximiliano Salinas se puede apreciar las iniciativas de los socialcristianos entre los trabajadores, profundizando Tracey Lynn Jaffe en la fructífera experiencia de la Juventud Obrera Católica chilena, JOC, entre las décadas de 1940 y 19605.

En relación a esos vínculos y relaciones, si bien es imposible señalar que la sola simpatía por otros líderes o corrientes políticas pudo alejar a no pocos obreros de las

\footnotetext{
${ }^{4}$ ROJAS, op. cit., p. 51.

5 PINTO, Julio. Trabajos y rebeldías en la pampa salitrera (1998); PINTO, Julio y VALDIVIA, Verónica, ¿Revolución proletaria o querida chusma? Socialismo y Alessandrismo en la pugna por la politización pampina (1911-1932) (2001); ROJAS, Jorge, La dictadura de Ibáñez y los sindicatos (1927-1931) (1993); SAGREDO, Rafael, Escritos del Padre Fernando Vives Solar (1993); SALINAS, Maximiliano Clotario Blest, profeta de dios contra el capitalismo (1987); JAFFE, Tracey Lynn, In the footsteps of Cristo obrero: Chile's Young catholic workers movement in the neighborhood, Factory, and family, 1946-1973. (2009).
} 
organizaciones de los trabajadores de izquierda, fueron otros los espacios que se avinieron mejor con aquellos que no participaban de las huelgas y no se sindicalizaban: las mutuales y cooperativas. Los historiadores marxistas reconocieron la influencia que habían alcanzado las primeras en los albores del movimiento obrero, no siguiendo su desarrollo tras el surgimiento de la corriente socialista entre los trabajadores, asumiendo tácitamente que habían perdido importancia y/o desaparecido, proyectando al sindicato (así como la fábrica y la sede partidaria), como "él" lugar donde estos habían desplegado su actividad y constituido su identidad.

Sin embargo, las mutuales y cooperativas no habían desaparecido ni vegetado tras la irrupción de las organizaciones ácratas y socialistas. Así, asumieron una creciente actividad durante los gobiernos reformistas de Arturo Alessandri y Carlos Ibáñez del Campo (1920-1931), con quienes se identificaron y de cuyas políticas se beneficiaron y, si bien se replegaron tras la caída del segundo y de la crisis económica de esos años, las orientaciones que fue adquiriendo la institucionalidad estatal surgida tras la crisis del régimen oligárquico facilitaron su desarrollo. En esa dirección, situando la temporalidad de este artículo en los inicios de los años cuarenta, el Estado de Compromiso implementó variadas iniciativas que las favorecieron, comenzando un proceso de expansión que en la década de los 60, con el apoyo de diversas instituciones y del gobierno demócrata cristiano de Eduardo Frei Montalva, las llevó a sumar a cientos de miles de socios. Alcanzando una dimensión e impacto que no se había observado desde comienzos de siglo y que no se repetiría a partir de los años setenta.

Las mutuales y cooperativas colocaron el énfasis en el esfuerzo colectivo, la comunidad de intereses y la cooperación, no en la reivindicación ni, mucho menos, en la lucha de clases, influyendo en los hábitos y prácticas de los obreros. Esos principios y prácticas en ningún caso impidieron que los sindicalistas y militantes de los partidos populares se sumaran a sus filas, recogiendo algunas de sus iniciativas y, probablemente, aportando a ellas con sus propias inquietudes y experiencias. Sin embargo, es posible deducir que, por las características y preocupaciones del mutualismo y el cooperativismo, así como por las prioridades e intereses de los militantes de izquierda, fueron los activistas de otras corrientes como los demócratas, 
nacionalistas, socialcristianos e independientes, quienes asumieron mayor protagonismo e influencia en ambos movimientos.

En relación a ese último punto, la influyente historiografía marxista puso énfasis (haciendo escuela) en la politización que los trabajadores vivieron en torno a los sindicatos y la praxis de la huelga, asociando "naturalmente" a la clase obrera con quienes promovían esos espacios y movilizaciones, las organizaciones y líderes de izquierda. Sin desconocer esa relación, como hipótesis planteamos que las mutuales y cooperativas se convirtieron en otra importante vertiente de politización popular, articulando a un significativo número de trabajadores de diversos orígenes, que estaban más preocupados por sus familias, vecinos o nación, que por su clase; facilitando su asociación con los proyectos que asumieron la dirección del Estado entre los años cuarenta y sesenta. Relacionando esa hipótesis con nuestra problematización inicial, se podría señalar que el apoyo popular que obtuvieron las fuerzas y candidatos que hablaban de honestidad y de orden, que apelaban a la familia y a la patria y, que planteaban cambios estructurales sin ruptura, habría que mirarlo como un proceso de largo aliento y de raíces profundas, dejando más de una huella en la identidad de los trabajadores.

De alcance nacional, la creación de mutuales y cooperativas, su número, diversidad y activismo, así como los escasísimos estudios sobre ellas en los años del Estado de Compromiso, ${ }^{6}$ dificultan una mirada de conjunto y una profundización en sus experiencias. La consulta de algunas fuentes, como su documentación interna, es posible solo para un muy pequeño grupo de organizaciones. Por ello, en términos metodológicos se optó, primero, por acotar este estudio a un espacio específico, la ciudad de Santiago, donde se formó la gran mayoría de las mutuales y cooperativas, se concentraron sus huestes y quedaron más “indicios” de su accionar; segundo, por

\footnotetext{
${ }^{6}$ La mayoría de los estudios que han abordado a las mutuales como tema específico, se han concentrado en su actividad entre fines del siglo XIX y comienzos del XX, siguiéndose poco su historia tras esos años. Entre varios otros, se pueden consultar los trabajos de DEVES, Eduardo, El pensamiento de Fermín Vivaceta y del Mutualismo en la segunda mitad del siglo XIX (1987); ESCOBAR, Dina, Asociación y mutualismo. Actitudes y comportamientos de artesanos y obreros. Santiago, 1880-1930 (1992); GODOY, Milton, Mutualismo y Educación: Las Escuelas Nocturnas de Artesanos, 1860-1880 (1994); ILLANES, María Angélica, La revolución solidaria. Las sociedades de socorros mutuos de artesanos y obreros: un proyecto popular democrático. 18401910 (2003); HOLLOWAY GUZMAN, Nicolás, Identidad, sociabilidad y política en el movimiento mutualista: la Sociedad de Artesanos 'La Unión' de Santiago, 1862-1888 (2007). Uno de los pocos trabajos que ha escapado a esa temporalidad es La trayectoria histórica del mutualismo en Chile (1853-1990): apuntes para su estudio (1994), de GREZ, Sergio.
} 
avanzar en la construcción de una panorámica general de lo que fue su actividad, con énfasis en sus eventos públicos, sus organismos coordinadores y los encuentros que realizaron, aspectos que, además de ser más rastreables en la prensa, permiten observar la expansión que habían alcanzado como movimiento; y tercero, por basarnos preferentemente en la prensa, que informó habitualmente sobre sus iniciativas. En relación a este último punto, fueron numerosos y variados los periódicos que siguieron de cerca el accionar de las mutuales y cooperativas, dando cuenta así no sólo de su cotidianeidad sino, además, del interés que despertaban entre las diversas corrientes de pensamiento que se expresaban en la prensa. De sus iniciativas informaron no solo sus propios medios, como La Gaceta Mutualista, de la Confederación Mutualista, y El Cooperado, sino también periódicos de vertiente católica, como Vida Obrera de la Acción Católica, y Tribuna Sindical, de la Asociación Sindical Chilena (ASICH, socialcristiana). Por su parte, medios vinculados a corrientes políticas también siguieron su accionar, destacando El Diario Ilustrado, del Partido Conservador, La Opinión, de tendencia socialista y El Imparcial, de posiciones centristas, así como La Nación, de propiedad del Estado, que en los años de los gobiernos del liberal Jorge Alessandri (1958-1964) y del demócrata cristiano Eduardo Frei Montalva (1964-1970), abrió sus páginas para informar sobre sus actividades.

Por último, a pesar que la información aportada por la prensa sobre las mutuales y cooperativas impide afirmar qué proporción de los trabajadores se sumaron a ellas o en qué medida influyeron sobre su identidad, la cotidianeidad de su presencia en los periódicos, la principal fuente de este escrito, es indicativo que eran parte del diario vivir de la población. A la par, la heterogeneidad de los medios que atendieron a sus iniciativas, manifiestan que, junto con ser parte de esa vida cotidiana, sus actividades no estaban acotadas a alguna organización o corriente política específica. $\mathrm{Y}$, aun cuando es imposible señalar que aquella diversidad de los medios que siguieron su accionar eran un reflejo de la heterogeneidad de los trabajadores, a partir de lo que proyectaban en sus páginas, sí se podría plantear que su mundo no estaba acotado ni a la fábrica, ni a los sindicatos, ni a las sedes de las organizaciones de izquierda. 


\section{Los orígenes del mutualismo y el cooperativismo}

Hasta fines de la primera mitad siglo XIX, los aún escasos trabajadores urbanos chilenos carecieron de espacios asociativos relevantes, organizándose algunos pocos gremios por iniciativa de los artesanos y del Estado, como los ebanistas de Santiago y Valparaíso y, los jornaleros y lancheros, respectivamente. 7 Esta situación comenzó a cambiar a partir de los años cincuenta, creándose las primeras mutuales por el impulso de tipógrafos y artesanos de la capital y el puerto, procurando atender, mediante el esfuerzo colectivo, la autogestión y el eventual apoyo material y legal del Estado, a las necesidades relacionadas con asistencia médica, previsión, educación y ayuda frente a accidentes o fallecimiento.

En los primeros años su crecimiento fue lento, existiendo apenas 13 en 1870, aumentando considerablemente hacia fines del siglo, sumando 76 en $1890 .{ }^{8}$ Una década después, decenas de mutuales formaron el Congreso Social Obrero (CSO), bajo la tutela del artesano Zenón Torrealba, en ese entonces un destacado militante del Partido Demócrata, ${ }^{9}$ sucediéndose en los años siguientes una serie de convenciones donde se fueron expresando sus proyectos y demandas, destacándose entre estas últimas la petición de leyes del trabajo y medidas contra la carestía de la vida. ${ }^{10}$ El apoyo que le prestaron los demócratas (así como los radicales), la disposición conciliadora que manifestaron y la experiencia asociativa que habían adquirido, así como el aumento de la masa laboral y la agudización de algunas de sus carencias, explican el crecimiento de las mutuales. Hacia 1910 existían 269 instituciones de ese tipo, elevándose su número en los años siguientes, llegando a alcanzar las 339 en 1923. A la par y no sin sobresaltos, mantuvieron su articulación, y si bien el Congreso Social Obrero fue afectado por el reflujo del campo popular tras la matanza de la Escuela Santa María en 1907, disminuyendo su funcionamiento en los

\footnotetext{
7 GREZ, Sergio, De la 'regeneración del pueblo' a la huelga general. Génesis y evolución histórica del movimiento popular en Chile (1810 - 1890), Santiago de Chile, RIL Editores, 2007, pp. 258 a 268.

${ }^{8}$ GREZ, Sergio, op. cit, pp. 439 a 445; PONCE, Homero, Historia del movimiento asociativo laboral chileno (Primer tomo, período 1838 - 1973), Santiago de Chile, autoedición, 1996, pp. 33 a 35.

${ }^{9}$ El Partido Demócrata fue fundado en 1887 por trabajadores de clase media (abogados, médicos), artesanos y obreros calificados, manifestando una importante influencia sobre la asociatividad popular de fines del siglo XIX y comienzos del XX. En relación a ello, Zenón Torrealba estuvo lejos de ser una excepción, siendo muchos otros los militantes del PD que tuvieron una participación destacada en las organizaciones de la época, situación que perduró hasta avanzados los años veinte, manteniendo presencia en algunas de ellas hasta la década de los 50.

${ }^{10}$ Según Julio César Jobet, en 1902 había 169 mutuales integradas al CSO, sumando aproximadamente 20.000 miembros, asistiendo a su V Congreso, realizado en 1907, 66 mutuales y 4 mancomunales. JOBET, Julio César, op. cit., p. 16, en su edición de 1973, en Santiago, por parte de Prensa Latinoamericana.
} 
años siguientes, en la década de 1920 volvieron a formarse coordinaciones mayores. Así, el Congreso Social Obrero se reorganizó en 1921 creándose poco después, en 1923/1925, la Confederación Nacional Mutualista, unificándose ambos referentes en 1926 y agrupando en su primer año de vida a 163 mutuales con un total de 127.000 socios. ${ }^{11} \mathrm{El}$ apoyo del Congreso Social Obrero a las reformas sociales y laborales que se impulsaron desde los golpes militares de 1924-1925, así como su identificación con el General Carlos Ibáñez del Campo, presidente entre 1927-1931, le granjeó las simpatías del Estado y de los trabajadores que se manifestaban de acuerdo con el proceso en curso, sufriendo luego el impacto del fracaso de la experiencia ibañista. De esa forma, en 1931, junto con el fin de la dictadura de Ibáñez, el CSO comenzó a debilitarse, no significando ello el fin del movimiento, pues el mutualismo se reorganizó nuevamente en torno a la Federación Provincial Mutualista en 1936 y la Confederación Mutualista en 1939.

El cooperativismo a su vez, no tuvo un mayor desarrollo en Chile durante la segunda mitad del siglo XIX, en buena medida por lo limitado de los recursos económicos del promedio de los trabajadores, lo cual les impedía disponer de un pequeño ahorro o capital para destinar a ese esfuerzo colectivo, orientado principalmente a satisfacer necesidades como el consumo y la vivienda. ${ }^{12}$ Las primeras décadas del siglo XX no fueron tampoco auspiciosas y si bien se formaron algunas, como las que impulsó el líder obrero Luis Emilio Recabarren, no se masificaron sino hasta los años veinte, cuando se comenzó a dictar una legislación que facilitaba su creación. En esa dirección, en 1924 se promulgó la Ley de Cooperativas ( $\mathrm{N}^{\circ}$ 4.058), la cual promovió su organización en torno al consumo, la vivienda y la producción, pasando de las apenas 6 existentes en 1925 a sumar 120 en $1930 .{ }^{13}$

\footnotetext{
${ }^{11}$ En esos mismos años, según Ramírez Necochea, la Federación Obrera de Chile (FOCH), orientada por el joven Partido Comunista, pasó de 60 mil afiliados en 1922, a 150 mil en 1925. RAMIREZ, Hernán, op. cit., p 225, en su edición del año 2007, en Santiago, por Editorial LOM. Jobet, por su parte, cifra en 100 mil los participantes de la Federación ese año. Op. cit., p. 190. Respecto a los referentes de vertiente ácrata, según Peter de Shazo, a comienzos de los años veinte la IWW alcanzó un máximo de 15 mil miembros, sumando apenas 3 mil, en Santiago, en 1925. Por su parte, de la Federación Obrera Regional de Chile (FORCH), creada en 1926, no se manejan cifras de asociados, coincidiéndose en que no alcanzó los contingentes de su predecesora. DE SHAZO, Peter, Trabajadores urbanos y sindicatos en Chile: 1902 - 1927, Santiago de Chile, DIBAM, 2007, p. 225.

${ }^{12}$ Sobre el desarrollo de las cooperativas en el siglo XIX ver a GREZ, Sergio, op. cit., pp. 446 a 451.

${ }^{13}$ PONCE, Homero, op. cit, pp. 218 a 222.
} 
Como las mutuales, aun cuando a un menor ritmo, las cooperativas también avanzaron en su articulación, creándose entre fines de los años 1930 y primeros de 1940, la Unión de Cooperativas de Huertos Obreros y Familiares, la Federación de Cooperativas de Huertos Obreros y la Confederación Nacional de Huertos y Jardines, las cuales, como veremos en las próximas páginas, tuvieron una significativa actividad a partir de mediados de siglo XX.

La lógica "positivista" de los párrafos previos no es antojadiza. Como señalaba en la introducción, los primeros investigadores que estudiaron a los trabajadores chilenos, si bien se refirieron a las mutuales y cooperativas, le prestaron muy escasa atención minimizando su presencia e influencia, concordando en que se habían ido debilitando ante la aparición desde comienzos del siglo XX de las sociedades en resistencia, mancomunales y federaciones. En relación a ello Ramírez Necochea señalaba que el Congreso Social Obrero había tenido una "lánguida existencia", pasando "en receso absoluto" largos años hasta su reactivación en 1921. El mismo autor indicaba críticamente, que en ese entonces el CSO fue una "expresión cabal de reformismo", manteniendo "una actitud de entendimiento permanente con el Gobierno de Alessandri" y aportando más tarde "una endeble base de masas" a la dictadura de Ibáñez. ${ }^{14}$ Según Jobet, algo menos crítico, el movimiento mutualista a pesar de su acción práctica en el mejoramiento económico de los sectores obreros y artesanos, "no tuvo mayor repercusión" entre ellos aun cuando había contribuido, "indirectamente", a "despertar la conciencia proletaria". ${ }^{15}$ Por último, para Barría el mutualismo por sus fines y composición heterogénea y policlasista, había jugado "un papel pasivo en la lucha social", reconociendo de todas formas que a partir de él había emergido "el sindicalismo como organismo clasista y dinámico,"16 afirmando que fue "perdiendo paulatinamente su influencia" por la promulgación de las leyes de seguridad social y por la actuación de otras organizaciones del movimiento obrero. ${ }^{17}$

Problematizando esa imagen, se puede observar que las mutuales prolongaron su existencia más allá de lo que habían afirmado los referidos historiadores y si bien la breve descripción realizada impide visualizar su influencia, es posible señalar que

\footnotetext{
${ }^{14}$ RAMIREZ, Hernán, op. cit., p. 228.

15 JOBET, Julio César, op. cit, p. 150.

${ }^{16}$ BARRIA, Jorge, El movimiento obrero en Chile, op. cit, p. 26, en su edición de 1971, en Santiago, por la Universidad Técnica del Estado.

${ }^{17}$ BARRIA, Jorge, op. cit, p. 56.
} 
fue mayor a la que plantean. En relación a ello, esos primeros investigadores coincidían en que las organizaciones que más tarde dieron forma a los sindicatos -las sociedades en resistencia y mancomunales-, incorporaron buena parte del acervo que habían creado las mutuales, pudiendo plantearse que la prolongación de su actividad dejó huella en el funcionamiento cotidiano de esos nuevos espacios y entre quienes los integraban. Eso explicaría, además, como veremos en las próximas páginas, la persistencia de su presencia y de las cooperativas en la asociatividad de los trabajadores chilenos entre las décadas de 1940 y 1960, desplegando una actividad que las llevó a sumar a miles de obreros, artesanos, empleados y pequeños productores, los cuales pudieron acceder a través de ellas a cultura, entretenimientos, consumo y vivienda, necesidades que escasamente cubría el Estado y que no podían satisfacer muchos/as asalariados del país.

\section{El viejo mutualismo en los años del Estado de Compromiso}

Según María Angélica Illanes, a fines de la década del 30 el movimiento mutualista, que contaba en ese entonces con 561 mutuales y 120 mil socios, se encontraba en una "nueva ofensiva" esperando a través del gobierno del Frente Popular (alianza de centro-izquierda compuesta por radicales, socialistas, comunistas y demócratas), participar en la gestión de las políticas implementadas desde la institucionalidad estatal, canalizando esa acometida a través de la Confederación Mutualista de Chile. ${ }^{18}$

Los acuerdos alcanzados en la convención que dieron origen a la confederación retomaban varias de las viejas demandas y preocupaciones del mutualismo, conectándolas con la nueva realidad institucional. Así, en el ámbito de la cultura se solicitaba del Estado subvención y equipamiento para las escuelas que administraban y becas para sus alumnos aventajados, pidiendo, a la par, participar en el consejo directivo de la Institución de Defensa de la Raza y Aprovechamiento de las Horas Libres. Respecto a salud, se requería que el Estado subvencionase a aquellas instituciones que prestaban servicios médicos y farmacéuticos, solicitando además estar representados en la Caja del Seguro Obrero y las Juntas de Beneficencia. En lo concerniente a la habitación, se pedían facilidades para adquirir y construir viviendas

\footnotetext{
${ }^{18}$ ILLANES, María Angélica, 'En el nombre del pueblo, del Estado y de la Ciencia...' Historia social de la Salud Pública. Chile 1880 - 1973, Santiago de Chile, Ministerio de Salud, 2010, p. 334.
} 
para sus socios, algo que obtendrían más tarde con la Ley Maza (1941), reclamando a la par que se tomaran medidas contra el encarecimiento de las "subsistencias". Por último, se planteaba la vieja demanda de que los mutualistas cotizasen legalmente en sus propias cajas de previsión y no en la Caja del Seguro Obrero Obligatorio.

En convenciones posteriores, tanto desde la Confederación Mutualista como de la Federación Provincial Mutualista, se insistió en algunas de esas ideas, como la formación de una caja de previsión para mutualistas, proponiéndose la creación de un banco y una compañía de seguros. A la par, se materializaron acciones para enfrentar el encarecimiento de la vida, sumándose la Confederación en 1945 a la coordinación anti especulación que existía entonces, representándola en esa instancia un destacado militante y dirigente del Partido Demócrata, Severo Samaniego Alarcón. ${ }^{19}$.

Las mutuales siguieron siendo predominantemente organizadas por trabajadores que compartían actividades, existiendo otras de alcance más transversal y/o de base territorial. Entre las primeras se encontraban las mutuales de empleados de comercio, de correos y telégrafos, de obreros municipales, de zapateros, panificadores y ferroviarios, entre muchos otros. Entre las segundas, la Sociedad Mutual de Ambos Sexos Javiera Larraín de Matte. Y entre las terceras, las sociedades que se formaron en las poblaciones Vicente Navarrete, Miguel Dávila y Germania.º En general, las mutuales (y cooperativas) se dieron una organización clásica, acorde además a las exigencias de la ley, con directivas pequeñas donde se asumían cargos específicos -presidente, vicepresidente, secretario de actas, tesorero y un par de directores-, ampliándose la participación de los socios a través del funcionamiento de comisiones permanentes o de existencia puntuales, como veremos en los párrafos siguientes. No es fácil saber, sin embargo, cuántas mutuales lograron mantener su actividad ni cuantificar la masa dirigencial que en su entorno se formó, pero la prensa deja entrever que fueron numerosas las que permanecieron en el tiempo y que varias decenas de socios se animaron a asumir obligaciones en ellas.

\footnotetext{
${ }^{19}$ El Siglo, 10 de noviembre de 1945, p. 9.

${ }^{20} \mathrm{Si}$ bien en Chile el término de usa con cierta laxitud, para la época que nos ocupa, una población era un asentamiento formal, surgido por iniciativa del Estado, las empresas o trabajadores organizados, que contaba con urbanización básica y viviendas terminadas o "planificadas". No eran asentamientos precarios o nacidos de forma espontánea, como las “poblaciones callampas", asimilables a los cantegriles uruguayos.
} 
Como veíamos previamente, el "nuevo impulso" del mutualismo portaba un fuerte cariz reivindicativo, no cejando en su clásico expediente de la autogestión para atender a las diversas necesidades de sus miembros. En esa dirección, en esos años mantuvieron servicios médicos, cuota mortuoria y gestionaron la construcción de poblaciones para sus socios. En el ámbito cultural fundaron bibliotecas y ateneos, entregaron premios a alumnos destacados de escuelas nocturnas, dictaron conferencias e impartieron cursos orientados al mundo del trabajo, mientras que en el campo deportivo y recreacional organizaron campeonatos, "Juegos Florales" (concursos literario-poéticos) y exhibiciones de cine, a la par que creaban clubes y grupos de scouts. ${ }^{21}$

En el impulso de esas iniciativas los mutualistas se relacionaron con autoridades comunales y estatales, empresarios, organizaciones barriales y sindicatos, quienes apoyaron, auspiciaron o participaron de sus actividades (además de promover las propias), compartiendo la preocupación por la formación cultural de los trabajadores, el goce de su tiempo libre y la satisfacción de algunas de sus necesidades básicas.22 Todo ello en un contexto social con altos índices de analfabetismo (20\% en 1952) y escasa calificación laboral, fuerte presencia del alcoholismo en los sectores populares -más de 80 mil chilenos/as padeciéndolo ese mismo año- y necesidades materiales no satisfechas.

Para algunos contemporáneos, la reactivación del mutualismo no sólo se explicaba por su propio impulso, sino también por las falencias del sindicalismo, que restó influencia dentro de la clase obrera. Así, en 1946 el Diario Ilustrado señalaba: "Una amarga experiencia de la vida, modalidades y actuaciones de los sindicatos que han abandonado su rol para embarcarse en aventuras políticas, ha vuelto a dar vida a las sociedades mutualistas". ${ }^{23}$

\footnotetext{
${ }^{21}$ La Opinión, “Alto grado de superación gremial demostró la clase obrera en 1949”, 1 de enero de 1950, p. 20; La Opinión, 27 de noviembre de 1950.

${ }^{22}$ En sus estudios sobre el "paternalismo industrial" en Chile en el siglo XX, Hernán Venegas y quienes han compartido su línea de investigación - Enzo Videla, Oscar Peñafiel, Diego Morales - han indagado en algunos aspectos de las políticas de bienestar promovidas por los empresarios, como la creación de lugares de esparcimiento y barrios obreros, y sus efectos sobre los trabajadores. Ver en VIDELA, Enzo; VENEGAS, Hernán; GODOY, Milton, El orden fabril. Paternalismo industrial en la minería chilena. 1900 - 1950 (2016).

${ }^{23}$ El Diario Ilustrado, Santiago, 20 de abril de 1946, p. 13, "Mutualistas en el puerto".
} 
En los años de "politización" del sindicalismo, que llevó a la ruptura de la Confederación de Trabajadores de Chile (CTCH) en 1946 y a su división hasta $1953,{ }^{24}$ las mutuales se mantuvieron fieles a sus tradiciones y propósitos (además de unidas), impulsando el mejoramiento de las condiciones de vida de sus socios, insistiendo en algunas de las demandas planteadas a comienzos de los años cuarenta -formación de una caja de previsión, de un banco y una compañía de seguros para los mutualistas- y fomentando aquellas prácticas que antaño buscaban la "regeneración del pueblo".

El abanico de actividades que impulsaron las mutuales en estos años abarcó ámbitos que, en muchos sentidos, ya estaban siendo atendidos por diversas instituciones - los sindicatos, la iglesia, los municipios -, manteniendo sin embargo diversos segmentos de trabajadores identificación con ellas ${ }^{25}$, reproduciendo en algunos de sus barrios la institución o sus prácticas.

La antiquísima Sociedad de Artesanos La Unión, fundada en 1862, mantenía una escuela técnica y organizaba periódicas conferencias, entre ellas sobre la educación de los niños, como la que tuvo lugar en octubre de 1949. La menos longeva Sociedad Mutualista Juan Miguel Dávila Baeza (1916), también administraba una escuela técnica, ${ }^{26}$ dando vida además al Club Ciclista Chacabuco. En pasos similares, la Sociedad de Socorros Mutuos Unión de Peluqueros (1901) que tenía bajo su alero al Club Deportivo Jorge Meléndez y la Sociedad Igualdad y Trabajo, organizó un campeonato de ping pong en 1949 con premios aportados por el Ministerio de Defensa y el alcalde de Quinta Normal. La Unión de los Tipógrafos, por su parte, realizaba gestiones en 1951 para que sus socios accedieran a viviendas en la chacra Ochagavía, en San Miguel, cuestión que ya había logrado la Sociedad Mutual y Deportiva Unión Ministerial en la población Vicente Navarrete, en el límite norte de esa comuna. Ejemplar, la Mutual de Choferes Manuel Montt, disponía para sus socios

\footnotetext{
${ }^{24}$ La división de 1946 se debió a la pugna entre los sindicalistas comunistas y socialistas por el control de la central, reproduciendo ese conflicto las tensiones que afectaban a dichos partidos en el plano político.

${ }^{25}$ De las aproximadamente 53 sociedades mutuales que se pudo identificar en la prensa de mediados de siglo pasado, poco menos de la mitad (25) se relacionaban expresamente con algún gremio u oficio. Entre ellos se encuentran los Obreros Municipales, Zapateros, Panificadores, Textil Hirmas, Tipógrafos y Mutual Hilandería San Miguel.

${ }^{26}$ Eran las viejas mutuales las que administraban escuelas técnicas. Considerando el conjunto, a través de sus cursos se podía aprender contabilidad, leyes tributarias, taquigrafía, corte y confección, carpintería, dibujo, tapicería, juguetería y muñecas en género, artes decorativas para el hogar y corte de camisa de hombre.
} 
de biblioteca, clínica médica, casino y mausoleo, procurando además acceder a créditos para que renovaran sus vehículos.

La proyección del mutualismo hacia los barrios obreros o populares tuvo sus ejemplos en estos años. Referíamos a la Sociedad Mutual Unión Ministerial, la cual gestionó viviendas de la Caja de Habitación Popular para sus socios en la población Vicente Navarrete, creándose precisamente en ese asentamiento la mutual homónima, que organizó un grupo scout y fomentó el atletismo, el ciclismo y el fútbol. La sociedad mutual de la población El Polígono, de Quinta Normal, también había formado un grupo scout, prestando ayuda económica además para enfrentar fallecimientos y asesoría para gestionar los títulos de dominio, promoviendo junto al municipio cursos de primeros auxilios para los vecinos.

Tales preocupaciones, que recordaban su perfil más clásico, se complementaron con otras que dieron cuenta de un mayor involucramiento con problemáticas que afectaban a los trabajadores en esos años, colocándolas, si no en confrontación con las autoridades del Estado, sí en tensión con ellas. En relación a lo anterior, recordábamos previamente que la Confederación Mutualista participaba en una coordinación anti especulación a mediados de los cuarenta, convergiendo en esa acción con la CTCH y los partidos demócrata y comunista, entre otros actores. En 1947 el aumento del costo de la vida continuó apremiando, acordando la Federación Mutualista en junio de ese año realizar un encuentro para discutir el tema de las subsistencias y el transporte público, enviando una nota al regidor Wenceslao Morales, en la cual le hacía notar las deficiencias del servicio de microbuses en los barrios apartados, pidiéndole las gestiones del caso para la solución de esas anomalías. Antes de finalizar la década, en octubre de 1949, el Primer Congreso Regional Mutualista se pronunció a favor de la implementación de la asignación familiar y la indemnización por año de servicio para los trabajadores, exigiendo además la aplicación efectiva de las leyes que los beneficiaban. Entre otras, las reformas de las leyes 4.054 y 4.055, las cuales habían dado origen al primer sistema de previsión dirigido a los obreros (la Caja del Seguro Obligatorio) y establecido una indemnización por accidentes del trabajo. ${ }^{27}$ Por su parte, en 1950, tanto la Federación

\footnotetext{
${ }^{27}$ La Gaceta Mutualista, Santiago, IV época, octubre de 1949, № 4, p. 2, “Celebración del día del mutualismo
} americano". Las leyes 4.054 y 4.055 eran parte del conjunto de leyes sociales dictadas en 1924. 
como la Confederación Mutualistas abordaron otra de las grandes carencias de la época, el techo, realizando la primera una charla sobre el tema en el mes de julio, invitando a esa actividad a un ingeniero, 28 mientras que la segunda organizó en setiembre un congreso nacional de la vivienda popular. La acumulación de demandas y la escasa respuesta llevó a una expresión pública del reclamo, titulando La Opinión en una edición de setiembre de 1951: "Protestan: 'En leyes sociales no se ha tomado en cuenta a Soc. de socorros mutuos". ${ }^{29}$

La disposición crítica no alejó sin embargo a las mutuales de su tradicional práctica de relación con el Estado, sus espacios y sus representantes. En febrero de 1948, cuando ya se estaba aplicando la "Ley Maldita" que había proscrito al Partido Comunista y limitado la actividad sindical, la Confederación expresó su apoyo al presidente Gabriel González Videla, cuestión que emuló la Confederación Nacional de Cooperativas de Huertos y Jardines de Chile en el mismo mes. En octubre de 1950 la Confederación Mutualista saludó la elección de quien fuera uno de sus fundadores, Adán Verde, para representar a las mutuales en el Consejo de la Caja de Habitación Popular, mientras que Leopoldo Sánchez, presidente de la Federación Mutualista en esos años, era electo regidor de la comuna de Santiago en 1953. Al acercarse el inicio de los preparativos del centenario del mutualismo chileno, las relaciones con los representantes del Estado se acentuaron, en un acto que tenía mucho más de simbolismo que de pragmatismo. Así, en noviembre de 1952 la Confederación y la Sociedad Unión de los Tipógrafos invitaron a una comida a los parlamentarios que habían obtenido para la mutualidad un importante aporte monetario para las futuras celebraciones, las cuales tenían ya incorporadas en su comité honorario al arzobispo de Santiago, a varios ministros, los presidentes del Senado y la Cámara de Diputados y, a su cabeza, el primer mandatario Carlos Ibáñez del Campo.

Con menos asociados que las organizaciones de carácter sindical, $3^{\circ}$ en estos años de mediados de siglo las mutuales tuvieron la virtud de la unidad y la

\footnotetext{
${ }^{28}$ La Opinión, 20 de julio de 1950, p. 4.

${ }^{29}$ La Opinión, Santiago, 14 setiembre de 1951, p. 4, "Protestan: 'En leyes sociales no se ha tomado en cuenta a Soc. de socorros mutuos".

${ }^{30}$ Según El Imparcial, al congreso de la Confederación Mutualista que se realizaría en abril de 1946 concurrirían 216 delegados, correspondiendo ellos a 186 mutuales donde se agrupaban unos 86.000 socios. Ver nota del 18 de abril de 1946, p. 14, "Congreso Mutualista". Respecto al sindicalismo, ese mismo año existían 591 sindicatos industriales y 1.115 profesionales, sumando los primeros poco más de 146.000 socios y, los segundos, 103.498,
} 
continuidad de sus tareas, impulsando actividades conjuntas -las celebraciones del día del mutualismo los 6 de octubre-, creando espacios como la "Casa de la Mutualidad" en 1946, difundiendo sus iniciativas a través de la radio -la "Hora Mutualista"- y realizando periódicamente sus propios encuentros. En uno de ellos en 1953, la referida Confederación llamó a formar "cooperativas de consumo", en auge desde la década previa.

Los acuerdos adoptados en aquel VII Congreso de la Confederación en abril de 1953 sintetizaban las demandas y expectativas del mutualismo chileno a una década y media de iniciada su reorganización y ad portas que la Sociedad Tipográfica cumpliera el centenario, articulando sus viejas preocupaciones con sus más nuevos y apremiantes intereses. La instrucción mantuvo su sitial de importancia, manifestándose por la creación de escuelas normales, proponiendo en el ámbito de la recreación y la asistencia la creación de un balneario mutualista e impulsando las "cooperativas de consumo". Más vinculados con las expectativas, discursos y necesidades de la época, propuso la incorporación de mutualistas en algunos organismos estatales, la participación obrera en las industrias, la construcción de viviendas y la reforma a las leyes 4.054 y $4.055 .{ }^{31}$

Ya centenario, el movimiento mutualista continuó organizando una serie de eventos durante toda la segunda mitad de los años cincuenta, manteniendo sus fuertes vínculos con sus viejos gremios y oficios, pero no permeando a nuevos sectores, perdiéndose de vista su cotidianeidad, la cual comenzaron a visibilizar los sindicatos y cooperativas, quienes absorbieron sus prácticas.

Congresos y encuentros similares se realizaron durante todos estos años, reproduciendo un hábito que no todos los trabajadores y sus organizaciones poseían. En abril de 1954 se llevó a cabo el $8^{\circ}$ Congreso Nacional Mutualista, asistiendo 108 delegados de mutuales de 25 provincias del país. $\mathrm{Al}$ año siguiente, a fines de octubre de 1955, se realizó un congreso regional de la Confederación Mutualista y la misma organización efectuó su $9^{\circ}$ Congreso en abril de 1957, comprometiendo la presencia

ello, de un total de Población Económicamente Activa de 2.025.837. En MORRIS, James; OYANEDER, Roberto, Afiliación y finanzas sindicales en Chile, 1932 - 1959, Santiago de Chile, INSORA, 1962, pp. 18 a 22.

${ }^{31}$ La Gaceta Mutualista, Santiago, IV época, junio de 1953, № 9, pp. 1 - 2 - 6 - 7, "Conclusiones del $7^{\circ}$ Congreso Mutualista de Temuco". El deporte era pensado también en otra dimensión, con una cartera ministerial que le diese impulso a la educación física y a prácticas deportivas que pudiesen combatir el alcoholismo. 
de más de 600 sociedades, las que representarían a unos 400.000 mutualistas..$^{2}$ Las mujeres mutualistas por su parte, a pesar de participar de esos encuentros, se propusieron organizar su propia convención a fines de 1959.

Las actividades y dinámicas clásicas del mutualismo siguieron, 33 no igualando el impulso del cooperativismo. Se mantuvo organizada hasta 1956 la Asociación Mutualista Deportiva, rebautizada a partir de ese año como Asociación Independiente de Deportes. En el mismo año, a partir del mes de agosto, la Federación Provincial Mutualista y aquellas sociedades que administraban escuelas llevaron a cabo sus Jornadas Culturales en la Casa Mutualista, presentando la primera conferencia el Rector de la Universidad Técnica del Estado, Santiago Labarca. Al año siguiente, en agosto de 1957, el diario Clarín informó que la Confederación Mutualista, mezclando las formas antiguas con las nuevas prioridades, organizaría un acto donde el tema central sería la cesantía.34 Por su parte, a fines de ese año la Federación Mutualista se reunión con el presidente Ibáñez para darle a conocer su visión sobre esa y otras problemáticas.

En la década de los sesenta la actividad del mutualismo se hizo menos visible, informando la prensa más de sus eventos mayores que de su funcionamiento cotidiano, siendo probable que parte de sus integrantes se hayan volcado a las múltiples organizaciones que se desarrollaron en esos años, tanto a nivel barrial como en el ámbito gremial, como Juntas de Vecinos y cooperativas. Con todo, durante la década se impulsaron encuentros y celebraron años de vida, como en 1961, cuando se organizó un congreso y se conmemoró el XXII aniversario de la Confederación Mutualista, instancia que se aprovechó para inaugurar un nuevo hogar social y la Biblioteca Arturo Alessandri, el ex presidente con el cual el mutualismo había tenido fuerte cercanía.35 A mitad de la década, en 1964, la referida Confederación decía tener 700 "entidades afiliadas", probablemente ya no todas mutuales, de ahí la laxitud de la

\footnotetext{
${ }^{32}$ Clarín, Santiago, 12 de abril de 1957, p. 2, “400 delegaciones asistirán al 9 Congreso Mutual”.

${ }^{33}$ Además del funcionamiento de varias de las antiguas sociedades, en los 50 se observó el surgimiento de algunas nuevas. De las sociedades clásicas, con un convencimiento apostólico continuaban, entre otras, la Unión de Tipógrafos, Unión Mutualista y Manuel Montt. De las sociedades nuevas estaban la de los trabajadores de Fanaloza Carrascal, la Mutual de los Viejos Cracks de Colo Colo y la de los pobladores de Los Nogales.

${ }^{34}$ El Siglo, Santiago, 11 de mayo de 1956, p. 7; Clarín, Santiago, 21 de agosto de 1957, p. 6, "De cesantía hablarán mañana en un acto de Central Mutualista".

${ }^{35}$ El Diario Ilustrado, Santiago, 1 de abril de 1961, p. 3, "Congreso mutualista"; La Nación, Santiago, 3 de abril de 1961, p. 13, "Crear un Banco de Ahorro para la vivienda acordaron los mutualistas"; El Diario Ilustrado, "Destacan laudables iniciativas del mutualismo en nuestro país", Santiago, 24 de febrero de 1964, p. 11.
} 
identificación, organizando un congreso en 1966. Por último, en abril de 1969, otro de los referentes del mutualismo, el Congreso Nacional Mutualista, realizó su XI Congreso y "Primero Constituyente", participando del evento 300 delegados. De esa forma, tras 30 años de reiniciado el "nuevo impulso" del mutualismo, décadas en las que se fortaleció el sindicalismo y creció el cooperativismo, sus referentes continuaban impulsando su actividad. $\mathbf{Y}$ si bien sus prácticas y principios no se adaptaban al escenario de polarización social y política que se estaba viviendo, sus esfuerzos por permanecer unidos y activos se mantenían.

\section{El ímpetu del cooperativismo en los años del Estado de Compromiso}

En los mismos años en que el mutualismo recobró parte de sus bríos -1940 a 1960-, se fueron masificando las cooperativas, un tipo de organización que si bien compartía características y propósitos con la primera, a comienzos del siglo no había logrado asentarse de forma importante entre los trabajadores.

Menguado su número hasta los años veinte, desde la década siguiente fueron aumentando sostenidamente, pasando de 120 en 1930 a 208 en 1945, explicándose ese crecimiento por una legislación que las siguió promoviendo, como la "Ley de Huertos y Jardines Obreros" de 1941 (la "Ley Maza”), que facilitó su creación para acceder a viviendas y espacios con fines productivos. También, por la compleja situación económica de esos años, correspondiendo 90 de ellas a cooperativas de consumo. ${ }^{6}$ Su creciente número y necesidad de asegurar el cumplimento de las leyes por parte de los poderes públicos, las llevó a coordinarse y dar origen a la Unión de Cooperativas de Huertos Obreros y Familiares, la Federación de Cooperativas de Huertos Obreros y la Confederación Nacional de Huertos y Jardines, realizando en estos años numerosas convenciones y congresos. Además de las cooperativas de huertos obreros, 37 las principales beneficiadas con la "Ley Maza", fueron organizadas otras que atendían necesidades variadas. Así, se formaron cooperativas de consumo la de Obreros Textiles Macul, de Empleados de la Empresa Nacional del Transporte, de los Ferroviarios- y cooperativas para acceder a la vivienda, como la Sociedad de Edificación El Hogar y de Obreros de la Construcción.

\footnotetext{
${ }^{36}$ Según Homero Ponce, en 1947 las cooperativas de consumo sumaban a 125.000 socios, ello de un total de 140.000 que agruparían como conjunto.

${ }^{37}$ Entre varias otras, la Sociedad Cooperativa Patria, Miguel Angel, Domingo Eyzaguirre y México.
} 
$\mathrm{Al}$ igual que el mutualismo, el cooperativismo procuró atender las necesidades básicas de sus integrantes, de ahí que una de sus preocupaciones centrales fuera el cabal cumplimiento de la Ley de Huertos y Jardines Obreros, lo cual incluía la inversión de la Caja de la Habitación en viviendas, demandándose su mejor funcionamiento y una mayor participación de las cooperativas en su accionar. A lo anterior, que puso a las cooperativas en contacto con la institucionalidad política y el aparato estatal, se sumó, bajo un evidente influjo mutualista, la atención a la asistencia social y la cultura, manteniendo por ejemplo la Confederación Nacional de Huertos y Jardines diversas secciones y servicios. Entre ellas, la de bienestar social, asesoría jurídica, biblioteca y casino cooperativo, fundando además el Instituto Cooperativo, donde se realizaban conferencias y estudios relacionados con el cultivo de huertos.

La división y repliegue del sindicalismo a fines de los años cuarenta y comienzos de los cincuenta, más el reflujo de parte de la movilización popular por la represión estatal, no afectó al cooperativismo que mantuvo el dinamismo que le había dado la Ley Maza de 1941. Si bien en esos años no llegó a emular el nuevo impulso de las mutuales, desarrolló una activa vida interna y se extendió hacia diversos sectores de trabajadores. Los tres principales referentes del cooperativismo impulsaron numerosas iniciativas en estos años, las cuales sirvieron para asentar el movimiento, dar a conocer lo que demandaban y tender puentes con las autoridades.

Encuentros de naturaleza más orgánica, como convenciones y/o congresos, realizaron la Unión de Cooperativas en agosto de 1945 y la Confederación Nacional en setiembre de 1947,38 mientras que en setiembre de 1951 las crecientemente importantes cooperativas de consumo organizaron su propio evento. En paralelo y al igual como ocurría con las mutuales, los cooperativistas celebraron año tras año su día -el 20 de diciembre-, siendo la ocasión propicia para mostrar sus progresos y tejer relaciones con las autoridades. En la conmemoración de 1949 ello se hizo patente, invitando a ministros, parlamentarios de diversas tendencias (socialcristianos, radicales, conservadores) y funcionarios de diversas reparticiones. La presencia de estas autoridades al parecer no era puramente formal, respondiendo al creciente

\footnotetext{
${ }^{38}$ El III Congreso de la Confederación, realizado en el fundo La Pintana, en la periferia sur de Santiago, administrado por la cooperativa José Maza.
} 
interés que fue despertando el cooperativismo. Así, desde mediados de la década de los cuarenta fue tema constante en la prensa de la Acción Católica, Vida Obrera, dedicándole casi una nota por número. A su vez, el muy completo periódico La Opinión informaba de sus eventos más importantes, señalando en relación a las cooperativas de ahorro en 1951 que eran organismos que "[habían] tenido un enorme auge especialmente en los barrios y sectores populares". 39 El Imparcial por su parte promovía el conocimiento y organización del cooperativismo, encontrándose en esa dirección una de varias notas publicadas en 1948, "Las cooperativas en Suecia", y dos notas de un número del año 1950, "Cómo debe entenderse el cooperativismo" y "Huertos familiares".40

Respecto a sus preocupaciones, el cumplimiento de la ley que había permitido su desarrollo -Ley de Huertos y Jardines Obreros-, fue la inquietud central de las cooperativas en estos años, cuestión que se tradujo en la exigencia de que la Caja de la Habitación Popular invirtiera efectivamente el $30 \%$ de sus recursos para la formación de huertos obreros y familiares y el $5 \%$ para el desarrollo de la industria casera, tal como establecía dicha ley. Junto a ello, a propósito de la reorganización de la Caja de la Habitación en 1943, se exigió la designación de consejeros activos y legítimos para representarlos en esa institución, una demanda que en su momento habían formulado también las mutuales. La formación de sus socios fue una tercera preocupación importante, organizando la Confederación Nacional el Instituto Cooperativo en 1949, mientras que en 1951 se creó el Centro de Estudios Cooperativos, participando uno de sus directivos en el congreso de cooperativas de ahorro de aquel año con una charla sobre el tema.41

Las cooperativas de huertos, representativas del conjunto en los primeros años, rápidamente fueron acompañadas por otras que respondían a necesidades diversas. A partir de las primeras surgieron asentamientos como las poblaciones Malaquías Concha y Julio Dávila, siguiendo la prensa de la época el funcionamiento de una decena de estos emprendimientos. Las cooperativas de consumo también fueron sumando adeptos, formándose en diversos lugares de trabajo y en algunas

\footnotetext{
${ }^{39}$ La Opinión, Santiago, 15 de setiembre de 1951, p. 4, "Congreso celebran las cooperativas de ahorro".

${ }^{40}$ El Imparcial, Santiago, 8 de febrero de 1948, p. 4, y 31 de enero de 1950, p. 4.

41 La Opinión, Santiago, 1 de octubre de 1951, p. 4, "Gran movimiento de cooperativas de ahorros en marcha: se unirán".
} 
poblaciones, como la Cooperativa de Consumo Población Vivaceta, que funcionaba en la práctica como una mutual, realizando cursos de alfabetización, charlas, conferencias y cine educativo, publicando por unos meses de 1948 el periódico El Cooperado. Creciente fue también la creación de cooperativas de construcción, como la Cooperativa Chile, que al igual que la cooperativa de la población Vivaceta, diversificó su actividad atendiendo además a la educación, el consumo y el ahorro. Este último tema, también como cooperativa, abarcaron los vecinos de la población El Carmelo, de San Miguel.

Como señalamos anteriormente, si bien el cooperativismo no igualó en estos años el desarrollo del mutualismo, las poco más de cincuenta cooperativas que se identificaron nominalmente o con alguna profundidad en la prensa, más lo variado del espectro laboral que participó de ellas, dan cuenta que alcanzó una creciente importancia entre los trabajadores. Entre otros gremios, promovieron su creación algunas organizaciones como la Federación Textil en su congreso de 1947, mientras que el Frente Nacional de la Vivienda formó en 1951 su cooperativa de construcción, llamada "La Casa Propia".

Durante la década de 1950 el cooperativismo mantuvo sus bríos, surgiendo cooperativas de todos los tipos, particularmente aquellas que respondían a dos de los grandes problemas de los trabajadores en esos años, signados por la inflación creciente y la disminución de la actividad económica: la carestía de la vida y el déficit de viviendas. Entre muchas otras, se formaron cooperativas de consumo de los trabajadores ferroviarios y lo propio hizo la Sociedad de Artesanos La Unión. Las cooperativas de edificación, por su parte, fueron parte del paisaje común de los trabajadores en los años cincuenta, constituyéndose, entre muchas otras, la Sociedad Cooperativa de Edificación de Viviendas Nueva Sierra Bella y la Sociedad de Edificación de Viviendas San Patricio, avanzando muchos trabajadores en la creación de otras, como los de FAMAE (Fábricas y Maestranzas del Ejército) y los obreros de la construcción. 
Desde fines de los años cincuenta, el crecimiento de las cooperativas fue notablemente positivo, ${ }^{42}$ fruto de la legislación que existía y de la que se siguió promulgando (como la Ley General de Cooperativas de 1960), del apoyo político del que disfrutaron y de la persistencia de algunas urgentes necesidades, como la vivienda. En términos de conjunto, en 1961 existían 628 cooperativas, llegando a 910 en 1963 y a 1.581 en 1967, más que duplicándose en sólo seis años, confirmándose una tendencia que se había iniciado con la ley misma que las había promovido en los años cuarenta. Al comenzar la década de los años sesenta, las cooperativas de vivienda sumaban 240 (con 240 mil socios), las de consumo, 231 (con 219.500 socios) y las de ahorro, 157 (con 40.175 socios), incrementándose todas hacia 1967. Así, ese año las cooperativas de vivienda eran 632, las de consumo, 255 y las de ahorro y crédito, $223^{43}$.

A la par de su crecimiento continuó su articulación, agrupándose un número relevante de ellas por ámbitos de trabajo, funcionando en los años sesenta la Federación Chilena de Cooperativas de Edificación de Viviendas, la Federación Nacional de Cooperativas de Consumo (nacida en 1954) y la Federación de Cooperativas de Ahorro y Préstamo,44 promoviéndose desde esos espacios la aprobación de legislación y políticas que las beneficiasen. En relación a ello, en el Primer Congreso Nacional de Cooperativas de Vivienda realizado en marzo de 1962, se solicitó la exención de impuestos y tributos a las cooperativas por diez años, la ayuda al Estado y los municipios para urbanizar sus poblaciones, más un "trato preferencial" a la CORVI en cuestión de plazos e intereses de pago.45 Sin saber cuál fue la respuesta inmediata a esas solicitudes, a fines de 1964 El Diario Ilustrado comentó sobre el positivo desarrollo que habían tenido las cooperativas y la opción

\footnotetext{
42 El Diario Ilustrado señalaba que en 1959 las cooperativas del país sumaban 412, con 311.000 socios "Notable incremento de cooperativas en el país", 9 de febrero de 1964, p. 20. Como referencia comparativa, ese mismo año 59, los sindicatos industriales sumaban 616, con 149.711 socios, y los profesionales alcanzaban los 1.116, con 110.933 integrantes. La Población Económicamente Activa, por su parte, totalizaba 2.739.698 personas. En MORRIS, James; OYANEDER, Roberto, op. cit., pp. 18 a 22.

${ }^{43}$ La Unión, Valparaíso, 5 de julio de 1967, p. 5, "Movimiento cooperativo".

${ }^{44}$ La Nación, Santiago, 9 de mayo de 1960, p. 18, "El cooperativismo de viviendas es un movimiento de vastas proyecciones". Según la nota, ese año había 223 cooperativas de vivienda, agrupando a 30.500 socios; El Mercurio, Santiago, 21 de setiembre de 1962, p. 18, "Conferencia nacional de cooperativas de consumo se efectuará en Santiago"; Vea, Santiago, 3 de enero de 1963, p. 19, "Cooperativas de ahorro hicieron préstamos que sumaron $\mathrm{E}^{\circ} 3.700 .000 "$ ".

${ }^{45}$ El Diario Ilustrado, Santiago, 2 de abril de 1962, p. 12, "Facilidades económicas acordó pedir congreso de cooperativas". Ese mismo año, la Federación Nacional de Cooperativas de Consumo realizaría una conferencia nacional en el mes de octubre. El Mercurio, Santiago, 21 de setiembre de 1962, p. 18, "Conferencia nacional de cooperativas de consumo se efectuará en Santiago".
} 
del gobierno entrante por impulsarlas, llamando la atención sobre los problemas que comenzaban a manifestar y generar. Básicamente, que estaban convirtiéndose en "competencia desleal" en los rubros en los cuales estaban incursionando, atrayendo a personas que no eran sus asociados o beneficiarios. 46

No fue casual la continuación del desarrollo de las cooperativas en los años sesenta. Sin estar libres de problemas, como alguna malversación de recursos, contaron con respaldo para la formación de sus directivos y socios, de un amplio conjunto de instituciones como el Departamento de Cooperativas de la Dirección de Industrias y Comercio (del Ministerio de Economía), la Universidad de Chile y la Universidad Católica. El referido Departamento de Cooperativas realizó, entre 1959 y 1963, 15 cursos sobre cooperativas y un seminario para gerentes de cooperativas de consumo, mientras que en enero de 1962 la Universidad de Chile organizó su "Primera Escuela de Verano de Conocimiento Sindical y Cooperativo". Por su parte, en junio de 1968 el Instituto de Cooperativismo de la Universidad Católica realizó un seminario que discutió la "Relación entre el Estado y las Cooperativas". Y a propósito de esa relación, el cooperativismo contó entre 1964 y 1970, con el importante apoyo del gobierno de la Democracia Cristiana, que las veía en esos años de auge del corporativismo y el anticomunismo, como una instancia de acción comunitaria sin contenidos clasistas. 47

En términos internos, las cooperativas impulsaron variadas iniciativas y lograron satisfacer diversas necesidades. En esa dirección, en enero de 1965 la Federación de Cooperativas de Ahorro y Préstamo realizaría un congreso nacional, con la participación de sus 12 comités regionales, mientras que en junio de 1966 la Federación de Cooperativas de Vivienda organizó su segundo congreso..$^{8}$ A su vez, la Federación Nacional de Cooperativas de Consumo conmemoró en 1964 el día del cooperativismo, informando por la prensa que la Federación administraba una

\footnotetext{
${ }^{46}$ El Diario Ilustrado, Santiago, 2 de abril de 1962, p. 12, "Facilidades económicas acordó pedir congreso de cooperativas"; El Diario Ilustrado, Santiago, 9 de noviembre de 1964, p. 11, "Legislación sobre cooperativas". No estaba del todo equivocado el periódico. A fines de 1965, Frei Montalva promulgaría un decreto que daría origen a la Comisión Nacional Coordinadora de Cooperativas.

${ }^{47}$ En relación a las organizaciones con contenido clasista, en el primer año de gobierno de la DC había 143.000 obreros incorporados a sindicatos industriales, 233.000 a profesionales y 1.700 a rurales, totalizando 270.000 sindicalizados. En ANGELL, Alan, Partidos políticos y movimiento obrero en Chile. De los orígenes hasta el triunfo de la Unidad Popular. México, Ediciones ERA, 1974, p. 64.

${ }^{48}$ Clarín, Santiago, 30 de setiembre de 1964, p. 10, "Cooperativismo al día".
} 
central óptica y una fábrica textil, importaba artefactos de uso doméstico para los socios, daba asesoría técnica y contable y en carpeta tenía la formación del Instituto de Crédito y Fomento Cooperativo.49 En el mismo año, 29 cooperativas de vivienda estaban tramitando la construcción de 3.202 casas y muchos socios aprovecharon los beneficios que estaban dando las cooperativas de consumo para satisfacer otras necesidades, bastante menos prioritarias. En relación a ello, en 1965 La Voz informó que el año previo la venta de televisores en una cooperativa había doblado a la venta de abarrotes y que los artículos suntuarios habían copado la mitad de su capacidad de ventas. $5^{\circ}$

No siendo generalizable al conjunto de las cooperativas, la situación referida por $L a$ Voz no era una mera excepción. Hacia los años sesenta, estas se habían asentado y formaban parte del paisaje asociativo de obreros y empleados, permitiendo que muchos de ellos accediesen a vivienda, consumo y préstamos, mejorando sustantivamente su pasar cotidiano. Para beneficio de un segmento importante de trabajadores, eso fue fruto de sus propias iniciativas y del apoyo estatal, complementando éste las políticas que, bajo su directa tutela, se promovían en los ámbitos social y laboral. De esa forma, a pesar de los límites que manifestó la política estatal impulsada desde los años 20, avanzado el siglo una proporción importante de trabajadores no se planteaban frente a los empresarios o el Estado en una lógica puramente dicotómica y demandante, encontrándose dispuestos a organizarse y movilizarse tanto para confrontarlos y exigirles, como para acordar iniciativas con ambos".

\section{Conclusiones}

Como señalábamos en la introducción, los historiadores que comenzaron a estudiar a los trabajadores en las décadas de 1950 y 1960, influidos por los fenómenos que maduraron en esos años, abordaron especialmente la historia del proletariado fabril y minero y, de ellos, la de quienes se habían vinculado a los procesos de organización, movilización y politización impulsados por corrientes y líderes de izquierda. Así, esas investigaciones dieron cuenta de los procesos de constitución de los sindicatos, federaciones y centrales, de las principales

\footnotetext{
${ }^{49}$ La Nación, Santiago, 11 de julio de 1964, p. 18, "Homenaje al Día Internacional del Cooperativismo".

${ }^{50}$ La Voz, Santiago, 6 de mayo de 1965, p. 13, "Mito y realidad del sistema cooperativo".
} 
movilizaciones que impulsaron, particularmente concentraciones y huelgas y, de los fuertes lazos que establecieron con los partidos populares, proyectando a esas organizaciones dinámicas y relaciones, si bien no únicas, sí predominantes entre los trabajadores.

Importantes sin duda esos espacios y prácticas, así como los vínculos que se promovieron y establecieron, hemos podido observar que los trabajadores también formaron y participaron en otras manifestaciones de la asociatividad popular, como las mutuales y cooperativas, expresiones que habían sido impulsadas desde las últimas décadas del siglo XIX.

En los años que abordamos -décadas de 1940 a 1960- aquellas viejas expresiones de la asociatividad popular no sólo seguían funcionando, sino que mantenían en pie numerosas iniciativas, como las mutuales, mientras que las cooperativas crecían y se especializaban. Como conjunto, fueron cientos de miles, fácilmente más de medio millón de obreros, empleados, artesanos y pequeños y medianos propietarios, quienes se integraron a estos espacios, manteniendo una actividad sistemática, permanente y muchas veces articulada, promoviendo la fraternidad y el trabajo conjunto entre los socios y la cooperación con la institucionalidad estatal. En su contraparte, las organizaciones de trabajadores sufrieron en estos mismos años su división y luego, una reunificación que estuvo constantemente tensada por las disputas y parcelaciones que se manifestaron en la Central Única de Trabajadores, gatilladas entre otras razones por las diferencias en las tácticas de lucha a impulsar y el tipo de relaciones que se debían establecer con el Estado.

Como dio a entender parte de la prensa de esos años, probablemente las tensiones y divisiones en el movimiento obrero facilitaron la incorporación de los trabajadores a las mutuales y cooperativas, encontrando en ellas la fraternidad y unidad de propósitos que declamaba el sindicalismo. A la par, su desarrollo se debió en buena medida, a la legislación que las promovió, a las instituciones que las apoyaron y al buen trato que le dispensaron las autoridades, las cuales veían su potencial para atender a algunas necesidades básicas y para atenuar el conflicto social fortaleciendo a los sectores más moderados, reconociendo además las coincidencias entre las prácticas, demandas y propuestas de ambos movimientos, con el ideario del 
Estado de Compromiso. Además de la importancia de esos apoyos e identificaciones, la permanencia y crecimiento de las mutuales y cooperativas se explica porque atendían a muchas de las inquietudes y necesidades de los trabajadores, como la vivienda, formándose muchísimos barrios de la capital por el esfuerzo de mutualistas y cooperativistas. A la par, miles de familias pudieron sortear la inflación de estos años incorporándose a cooperativas de consumo. Otras tantas pudieron formar un pequeño capital en aquellas que apuntaban al ahorro, mientras muchas otras accedieron a la cultura, el deporte y la educación a través de las iniciativas que impulsaron las mutuales.

Por último, difícil sería señalar que la prolongada y profunda relación que establecieron los trabajadores con las mutuales y cooperativas, no incidió en sus hábitos, valores y prácticas. En relación a ello, el propio funcionamiento de estas, constante y sistemático, reforzó los viejos principios de trabajo de artesanos y obreros calificados, quienes seguían siendo protagonistas en sus filas. Los orígenes de estas entidades en el liberalismo popular y los vínculos que desarrollaron en el tiempo con el reformismo alessandrista, el nacionalismo ibañista y el socialcristianismo de los católicos progresistas, las permeó del imaginario del progreso y el bien común, las alejó del discurso clasista y las dispuso favorablemente a la relación con la institucionalidad estatal. De esa forma, los trabajadores que integraron las mutuales y cooperativas fueron forjando una identidad donde confluyeron las experiencias de esos espacios, de la fábrica y la vivida en sus barrios, atenuándose la vertiente más antipatronal, clasista y reactiva al Estado, que habían heredado del sindicato. Así, entre un número importante y diverso de trabajadores chilenos, pudieron proyectarse los discursos que colocaron el acento en el bien común, el esfuerzo colectivo y la cooperación, quedando permeables a las propuestas políticas que entre las décadas de 1940 y 1960, prometían responsabilidad y honestidad, unidad nacional y transformaciones sin rupturas. 


\section{Bibliografía:}

\section{Libros:}

ANGELL, Alan, Partidos políticos y movimiento obrero en Chile. De los orígenes hasta el triunfo de la Unidad Popular. México, Ediciones ERA, 1974.

BARRIA, Jorge, El movimiento obrero en Chile. Santiago de Chile, Ediciones de la Universidad Técnica del Estado, 1971.

GREZ, Sergio, El Partido Democrático de Chile. Auge y caída de una organización político popular (1887-1927). Santiago de Chile, LOM Ediciones, 2016.

ILLANES, María Angélica, 'En el nombre del pueblo, del Estado y de la Ciencia... Historia social de la Salud Pública. Chile 1880 - 1973. Santiago de Chile, Ministerio de Salud, 2010.

JOBET, Julio Cesar, Recabarren y los orígenes del movimiento obrero y el socialismo chilenos. Santiago de Chile, Editorial Prensa Latinoamericana, 1973

MORRIS, James; OYANEDER, Roberto, Afiliación y finanzas sindicales en Chile, 1932 - 1959. Santiago de Chile, INSORA, 1962.

PINTO, Julio, Trabajos y rebeldías en la pampa salitrera. Santiago de Chile, Editorial Universidad de Santiago, 1998.

PINTO, Julio; VALDIVIA, Verónica, ¿Revolución proletaria o querida chusma? Socialismo y Alessandrismo en la pugna por la politización pampina (1911 1932). Santiago de Chile, LOM Ediciones, 2001.

PONCE, Homero, Historia del movimiento asociativo laboral chileno (Primer tomo, período 1838 - 1973). Santiago de Chile, Autoedición, 1996.

RAMIREZ, Hernán, Obras Escogidas. Volumen III. Origen y formación del Partido Comunista de Chile. Ensayo de historia política y social de Chile. Santiago de Chile, LOM Ediciones, 2007.

ROJAS, Jorge, La dictadura de Ibáñez y los sindicatos (1927-1931). Santiago de Chile, DIBAM, 1993.

SAGREDO, Rafael, Escritos del Padre Fernando Vives Solar. Santiago de Chile, DIBAM, 1993.

SALINAS, Maximiliano, Clotario Blest, profeta de dios contra el capitalismo. Santiago de Chile, Ediciones REHUE, 1987.

DE SHAZO, Peter, Trabajadores urbanos y sindicatos en Chile: 1902 - 1927. Santiago de Chile, DIBAM, 2007.

VITALE, Luis, Interpretación marxista de la historia de Chile. Santiago de Chile, LOM Ediciones, 2011.

VIDELA, Enzo; VENEGAS, Hernán; GODOY, Milton (ed.), El orden fabril. Paternalismo industrial en la minería chilena. 1900-1950. Valparaíso, Chile, Editorial América en Movimiento, 2016.

\section{Capítulos de libros:}


DEVES, Eduardo, "El pensamiento de Fermín Vivaceta y del Mutualismo en la segunda mitad del siglo XIX". En Mario BERRIOS y otros, Pensamiento en Chile 1830-1910. Chile, Estudios Latinoamericanos, 1987, $\mathrm{s} / \mathrm{n}^{\circ} \mathrm{p}$.

ILLANES, María Angélica, "La revolución solidaria. Las sociedades de socorros mutuos de artesanos y obreros: un proyecto popular democrático. 1840-1910". En María Angélica ILLANES, Chile des-centrado. Formación socio-cultural republicana y transición capitalista (1810-1910). Santiago, LOM Ediciones, 2003, pp. 267 a 366.

\section{Artículos:}

GODOY, Milton, "Mutualismo y Educación: Las Escuelas Nocturnas de Artesanos, 1860-1880”. Última Década, No 2, agosto de 1994, pp. 1 a 11.

GREZ, Sergio, "La trayectoria histórica del mutualismo en Chile (1853-1990): apuntes para su estudio". Revista Mapocho, No 35, 1994, pp. 293 a 316.

ROJAS, Jorge, "Los trabajadores en la historiografía chilena: balances y proyecciones”. Revista de Economía y Trabajo, Dirección del Trabajo, № ${ }_{10}$, 2000, pp. 47 - 117.

\section{Tesis:}

ESCOBAR, Dina, Asociación y mutalismo. Actitudes y comportamientos de artesanos y obreros. Santiago, 1880-1930. Universidad de Chile, Tesis Magister de Historia, 1992.

HOLLOWAY GUZMAN, Nicolás, Identidad, sociabilidad y política en el movimiento mutualista: la Sociedad de Artesanos 'La Unión' de Santiago, 1862-1888. Universidad de Chile, Tesis Licenciatura en Historia, 2007.

JAFFE, Tracey Lynn, In the footsteps of Cristo obrero: Chile's Young catholic workers movement in the neighborhood, Factory, and family, 1946-1973. Estados Unidos, University of Pittsburgh, Tesis Doctoral, 2009.

\section{Diarios:}

Con excepción de La Unión, la prensa consultada fue impresa en Santiago de Chile.

Consultados en la Sección Periódicos de la Biblioteca Nacional:

Clarín

El Cooperado

El Diario Ilustrado

El Imparcial

El Siglo

Gaceta Mutualista

La Gaceta Mutualista

La Opinión 


\section{Tribuna Sindical}

\section{Vida Obrera}

Consultados en el Archivo de Prensa y Procesamiento de Datos de la Biblioteca del Congreso Nacional de Chile:

\section{La Nación}

\section{La Tercera de la Hora}

\section{La Voz}

La Unión (Valparaíso)

\section{El Mercurio}

Vea 